\title{
The Dual Effect of Abnormal Serum Uric Acid on Intervertebral Disc Degeneration
}

\author{
Ming Yang $\mathbb{D}^{1,2}$ Naiguo Wang $\mathbb{D}^{3}$ Wentao Zhang $\mathbb{D}^{1,2}$ Tianze Sun $\mathbb{D}^{1,2}$ Dan Zhang $\mathbb{D}^{1,2}$ \\ Yvang Chang $\mathbb{D},{ }^{1,2}$ Jingmin $L i \mathbb{D}^{4},{ }^{4}$ and Zhonghai $L i \mathbb{D}^{1,2}$ \\ ${ }^{1}$ Department of Orthopaedics, First Affiliated Hospital of Dalian Medical University, Dalian, China \\ ${ }^{2}$ Key Laboratory of Molecular Mechanism for Repair and Remodeling of Orthopaedic Diseases, Liaoning Province, China \\ ${ }^{3}$ Department of Spinal Surgery, Shandong Provincial Hospital, Cheeloo College of Medicine, Shandong University, Jinan, China \\ ${ }^{4}$ Key Laboratory for Micro/Nano Technology and System of Liaoning Province, Dalian University of Technology, Dalian, China
}

Correspondence should be addressed to Zhonghai Li; lizhonghaispine@126.com

Received 9 July 2021; Accepted 18 September 2021; Published 29 September 2021

Academic Editor: Feng-Dong Zhao

Copyright (c) 2021 Ming Yang et al. This is an open access article distributed under the Creative Commons Attribution License, which permits unrestricted use, distribution, and reproduction in any medium, provided the original work is properly cited.

An abnormal serum uric acid (SUA) level is associated with many diseases. To our knowledge, there is no research on the association between SUA and intervertebral disc degeneration (IDD). The purpose of this study was to determine the relationship between SUA and IDD. From June 2011 to July 2020, 691 patients undergoing surgery for lumbar disc herniation (LDH) were included in the LDH group, and 684 patients who underwent endoscopic surgery for knee trauma were included in the non-LDH group. We examined the baseline characteristics of all these patients and divided the SUA level into 10 groups according to the percentiles in males, females, and the total population. Subsequently, the relationship between the SUA level and IDD was further analyzed. There was no statistically significant difference in the baseline characteristics of the two groups $(p>0.05)$. Among the 10 groups, the $\mathrm{LDH}$ rate was higher at both lower and higher SUA levels. In multiple logistic regression analysis, after adjustment for age, sex, body mass index, smoking, and drinking, when the SUA level was $<20 \%$ or $>80 \%$, compared with $60-80 \%$, the odds ratio (OR) and 95\% confidence interval (CI) of LDH of the total population were 1.821 (1.125-2.946) and 1.701 (1.186-2.438), respectively, and in the males, they were $1.922(1.169-3.161)$ and $2.800(1.766,4.439)$, respectively. In females, when the SUA was $<20 \%$, there was a higher $\mathrm{LDH}$ rate $(\mathrm{OR}=1.951,95 \% \mathrm{CI} 1.091-3.486)$. The present study suggests that there is a U-shaped relationship between SUA and IDD, being particularly prominent among male. Lower and higher SUA level may be risk factors for IDD.

\section{Introduction}

Lumbar disc herniation (LDH) is a disease caused by intervertebral disc (IVD) degeneration (IDD). IDD is a physiological and pathological process of progressive aging and degeneration of the IVD structure. The occurrence of this degeneration can lead to an imbalance of the internal IVD environment, the loss of tissue hydration, inflammation, and an extracellular matrix (ECM) loss, which in turn leads to a decrease in the IVD height, destruction of the annulus fibrosus structure, and a gradual loss of normal physiological structure and function [1]. IDD is the pathological basis of $\mathrm{LDH}$, spinal stenosis, and other related diseases, and it is also one of the main causes of cervical spondylosis and low back pain [2]. These diseases seriously affect the quality of life of patients and represent a huge economic burden to society. The occurrence of IDD is determined largely by genetic factors, mechanical stress, trauma, and nutrition among others [3]. These factors act on the IVD nucleus pulposus and annulus fibrosus tissues and ultimately lead to degenerative changes of the IVD.

Uric acid (UA) is the end product of purine metabolism. Humans lack the enzyme urate oxidase; therefore, the serum UA (SUA) level in human plasma is higher compared with that in most other mammals [4]. When the SUA level exceeds saturation, monosodium urate precipitates and deposits on the peripheral joints and surrounding tissues, where it can cause gout. When the SUA level in male is 
$>420 \mu \mathrm{mol} / \mathrm{l}$ and in females is $>360 \mu \mathrm{mol} / \mathrm{l}$, this is termed hyperuricemia (HUA) [4]. HUA is a metabolic disease caused by excessive secretion or insufficient excretion of SUA. The prevalence of HUA is increasing globally. An epidemiological survey showed that the HUA prevalence in males and females from 2015 to 2016 was $20.2 \%$ (22.8 million) and $20.0 \%$ (24.4 million), respectively [5]. HUA is closely associated with metabolic syndrome, kidney disease, cardiovascular and cerebrovascular diseases, and mortality [4]. By contrast, UA is an antioxidant and neuroprotector [6]. Du et al. [7] confirmed that UA has a protective effect on spinal cord nerve injury. A meta-analysis study by Pan et al. [8] showed that UA may be a protective factor for Alzheimer's disease. In addition, reduction of UA level is also associated with the increased risk of oral, lung, and laryngeal cancers [9].

The question arises as to whether there is a correlation between abnormal SUA and IDD. Earlier, some case reports described the observation of UA crystals in the lumbar discs of some gout patients with low back pain and lower limb radiating pain $[10,11]$. These cases suggested that there may be an association between SUA and IDD. We previously hypothesized that given the nature of UA, it may have a dual effect on the IVD [12]. The question was raised whether this effect of SUA on IDD is similar to other diseases. To explore the relationship between HUA and IDD, we conducted a retrospective case-control study to compare the SUA level between patients with LDH and knee trauma patients without $\mathrm{LDH}$ and further analyzed the relationship between IDD and the SUA level. To the best of our knowledge, the present study is the first report to focus specifically on the correlation between the SUA level and IDD.

\section{Materials and Methods}

2.1. Study Population. This was a retrospective case-control clinical study. From June 2011 to July 2020, a total of 1375 patients were recruited for this study. The LDH group included 691 patients (422 males and 269 females; male age: 39.4 years, range $19-58$ years) who underwent surgery for $\mathrm{LDH}$. The non-LDH group (control group) included 684 patients (425 males and 259 females; male age: 40.0 years, range 18-58 years) who underwent arthroscopic surgery because of knee injury during the same period. Patients in the non-LDH group were collected randomly from among patients who were age- and sex-matched patients with the LDH group.

Inclusion criteria in the LDH group were (1) 18-60 years old, (2) had nerve root irritation (positive straight leg elevation test) or neurological dysfunction (motor weakness, numbness, or lack of corresponding reflexes), (3) magnetic resonance imaging signs of herniated disc, and (4) refractory radicular pain despite adequate medical treatment. Exclusion criteria were (1) age $<18$ or $>60$ and (2) the patient has a history of spinal trauma, tumor, tuberculosis, ankylosing spondylitis, rheumatism, diabetes, hypertension, or dyslipidemia.

Inclusion criteria in the non-LDH group were (1) 18-60 years old, (2) with a history of acute trauma and clinically and imaging diagnosis of knee ligament or meniscus injury, and (3) the injury had a surgical indication. Exclusion criteria were (1) age $<18$ or $>60$; (2) displayed nerve root irritation, low back pain, and LDH; and (3) have a history of tumor, tuberculosis, rheumatism, diabetes, hypertension, or dyslipidemia.

2.2. Data Collection and Outcome Evaluations. We collected patient information through the electronic medical record system, and the study was approved by the Ethics Committee of the First Affiliated Hospital of Dalian Medical University (PJ-KS-KY-2021-86). Confirmation was obtained that all patients gave written informed consent. The fasting SUA of all the patients was tested on the second day after admission. To analyze the effect of the SUA concentration on IDD more accurately, the subjects were categorized into ten groups according to the deciles of the SUA level. The 10 groups of male patients were $\leq 276,277-303,304-328$, $329-352$, 353-372, 373-392, 393-414, 415-443, 444-495, and $\geq 496 \mu \mathrm{mol} / \mathrm{l}$; those of the females were $\leq 198,199-220$, 221-237, 238-252, 253-265, 266-282, 283-303, 304-334, $335-364$, and $\geq 365 \mu \mathrm{mol} / \mathrm{l}$; and of the total patients were $\leq 222$, 223-256, 257-281, 282-306, 307-333, 334-358, 359$384,385-412,413-464$, and $\geq 465 \mu \mathrm{mol} / \mathrm{l}$ (Table 1 ).

2.3. Statistical Analysis. All continuous variables were presented mean (SD, standard deviation) and compared by one-way ANOVA and the Bonferroni test or $t$-test. Categorical variables were presented as the count and percentage and compared by $\chi^{2}$ test. Univariate and multiple logistic regression analyses were used to evaluate the effect of SUA on the IVD. All statistical analysis were performed using the Statistical Package for Social Sciences (v.23.0, IBM Statistics, Armonk, NY,USA) and R software (version 3.30) with $p<0.05$ considered statistically significant.

The pattern of quantitatively assessed SUA-associated IDD occurrence was analyzed by restricted cubic splines (RCS) that display the odds ratio (OR) on the $y$-axis versus the metric used to quantify the SUA level on the $x$ -axis, whereby an OR of 1 indicates a reference value (cut-point), OR $>1$ represents the risk of patients displaying IDD, and $\mathrm{HR}<1$ indicates a lower risk for IDD. Because of the sex-specific differences in SUA, the analyses were stratified by sex.

\section{Results}

3.1. Baseline Characteristics. A summary of the baseline characteristics of the 1375 patients enrolled in the study is presented in Table 2 . There was no statistically significant difference between the case and control groups in sex, age, BMI, smoking, or drinking ( $p>0.05)$.

3.2. Association between SUA and IDD. In the 10 groups of total patients, as the SUA level increased, the proportion of male patients gradually increased. In the same percentile group, male patients have higher SUA level than female patients. In the total patients, the LDH rate was higher in the first, second, and last deciles, and it attained a minimum in the eighth decile. Almost the same pattern was also 
TABle 1: Deciles of SUA $(\mu \mathrm{mol} / \mathrm{l})$.

\begin{tabular}{lcccccccccc}
\hline \multirow{2}{*}{ Characteristics } & D1 & D2 & D3 & D4 & D5 & D6 & D7 & D8 & D9 & D10 \\
& $\leq 10 \%$ & $10 \%-20 \%$ & $20 \%-30 \%$ & $30 \%-40 \%$ & $40 \%-50 \%$ & $50 \%-60 \%$ & $60 \%-70 \%$ & $70 \%-80 \%$ & $80 \%-90 \%$ & $\geq 90 \%$ \\
\hline Total & $\leq 222$ & $223-256$ & $257-281$ & $282-306$ & $307-333$ & $334-358$ & $359-384$ & $385-412$ & $413-464$ & $\geq 465$ \\
Male & $\leq 276$ & $277-303$ & $304-328$ & $329-352$ & $353-372$ & $373-392$ & $393-414$ & $415-443$ & $444-495$ & $\geq 496$ \\
Female & $\leq 198$ & $199-220$ & $221-237$ & $238-252$ & $253-265$ & $266-282$ & $283-303$ & $304-334$ & $335-364$ & $\geq 465$ \\
\hline
\end{tabular}

SUA: serum uric acid.

TABLE 2: The baseline characteristics of study subjects.

\begin{tabular}{lccc}
\hline Characteristics & $\begin{array}{c}\text { LDH group } \\
n=691\end{array}$ & $\begin{array}{c}\text { Non-LDH group } \\
n=684\end{array}$ & $p$ value \\
\hline Sex (male/female) & $422 / 269$ & $425 / 259$ & 0.685 \\
Age (years) & $39.3 \pm 9.0$ & $40.0 \pm 9.0$ & 0.189 \\
Range (years) & $19-58$ & $18-58$ & \\
BMI (kg/m $\left.{ }^{2}\right)$ & $25.3 \pm 4.5$ & $25.1 \pm 4.6$ & 0.559 \\
Smoking (yes/no) & $158 / 533$ & $145 / 539$ & 0.456 \\
Drinking (yes/no) & $72 / 619$ & $66 / 618$ & 0.634 \\
SUA ( $\mu \mathrm{mol} / \mathrm{l})$ & $339.4 \pm 101.2$ & $338.2 \pm 89.4$ & 0.820 \\
\hline
\end{tabular}

Data on age and BMI are given as the means \pm SD and analyzed with independent-sample $t$-tests. Data on sex, smoking, and drinking are analyzed with $\chi 2$-test. LDH: lumbar disc herniation; BMI: body mass index; SUA: serum uric acid.

observed in the male and female participants, with the $\mathrm{LDH}$ rate being higher at lower and higher SUA levels compared with that at the intermediate level (Table 3). Results from smoothing spline plots suggested that SUA displayed a Ushaped association with $\mathrm{LDH}$. The results of restricted cubic spline regression analysis showed that SUA was a risk factor $(\mathrm{OR}>1)$ for $\mathrm{LDH}$ when the SUA level was less than $263.5 \mu \mathrm{mol} / \mathrm{l}$ or $356.2 \mu \mathrm{mol} / 1$ before adjusting age, BMI, smoking, and drinking in the male population (Figure 1). After adjusting for these factors, the two values were $265.3 \mu \mathrm{mol} / \mathrm{l}$ and $363.6 \mu \mathrm{mol} / \mathrm{l}$, respectively (Figure 2). In the female group, the two values before adjustment were $326.5 \mu \mathrm{mol} / \mathrm{l}$ and $375.7 \mu \mathrm{mol} / \mathrm{l}$, respectively (Figure 3), and after adjustment, they were $324.1 \mu \mathrm{mol} / \mathrm{l}$ and $375.6 \mu \mathrm{mol} / \mathrm{l}$, respectively (Figure 4).

Univariate logistic regression analysis was performed with the occurrence of IDD in the study subjects as the dependent variable and the amount and concentration of SUA as the independent variable (Table 4). Compared with the $60-80 \%$ interval SUA, when SUA was $<20 \%$, the OR of the male population was 1.764 (95\% CI: 1.144-2.719, $p=0.010)$, the OR of the female population was 1.788 (95\% CI: $1.032-3.097, p=0.038$ ), and the OR of the total population was 1.693 (95\% CI: $1.209-2.372, p=0.002)$; when the SUA interval was $>80 \%$, the OR of the male population was 2.687 (95\% CI: $1.726-4.182, p<0.001)$, and the OR of the total population was 1.675 (95\% CI: $1.194-$ 2.349, $p=0.003$ ).

In multiple logistic regression analysis, after adjustment for age, sex, BMI, smoking, and drinking, compared with the $60-80 \%$ interval SUA, when SUA was $<20 \%$, the OR of the male population was 1.922 (95\% CI: 1.169-3.161, $p=0.010)$, the $\mathrm{OR}$ of the female population was 1.951 (95\% CI: $1.091-3.486, p=0.024$ ), and the OR of the total population was 1.821 (95\% CI: $1.125-2.946, p=0.015$ ); when the SUA interval was $>80 \%$, the OR of the male population was 2.800 (95\% CI: $1.766-4.439, p<0.001$ ), and the OR of the total population was 1.701 (95\% CI: $1.186-$ $2.438, p=0.004$ ) (Table 5). The results showed that lower and higher SUA levels were a risk factor for IDD.

\section{Discussion}

The IVD is the fibrous tissue that connects the upper and lower vertebral bodies, maintains the normal height of the intervertebral space, and constitutes the main functional unit of the spinal motion segment. It consists of the central nucleus pulposus, surrounding fibrous annulus, and upper and lower cartilage endplates [13]. The nucleus pulposus is gelatinous and mainly composed of nucleus pulposus cells and ECM components. Its matrix components are mainly composed of type II collagen fiber water, proteoglycan, and water $[14,15]$. The annulus fibrosus is a ring-shaped structure surrounding the nucleus pulposus and is composed of 15-25 layers of collagen-rich fibrous connective tissue; the inner annulus layer is mainly type II collagen, whereas the outer layer is mainly type I collagen [16]. The cartilage endplate is composed of hyaline cartilage, which is the nutritional pathway of the IVD $[3,15]$.

The IVD is the largest avascular tissue in the human body. Only a few capillaries are distributed in the cartilage endplate and annulus fibrosus, such that only a part of the nutrients diffuse from the capillaries into the IVD, while the remainder diffuses inwards from the cartilage endplate along the concentration gradient [17-19]. Because of the special structure and function of the IVD, as the body ages, the IVD is prone to degenerative changes. IDD is attributed to the complex interaction between environmental and genetic factors. The degeneration process includes the reduction of the nutrient supply and changes in the ECM composition. With increasing age, the cartilage endplate begins to calcify, thereby progressively reducing the penetration of nutrients and oxygen into the nucleus pulposus [20]. At this time, the role of capillary nutrition pathways becomes more important. Some studies found that the LDH incidence in patients with atherosclerosis is increased, suggesting that atherosclerosis will affect the nutrient supply of the IVD $[21,22]$. The change of the internal environment of the IVD is also an important factor in IDD. Factors such as apoptosis, nutritional disorders, mechanical load, and 
TABLE 3: The baseline characteristics, SUA level, and rate of IDD of 10 groups.

\begin{tabular}{|c|c|c|c|c|c|c|c|c|c|c|c|c|}
\hline \multirow{2}{*}{ Characteristics } & \multicolumn{4}{|c|}{ Deciles of SUA } & \multirow[b]{2}{*}{ D4 } & \multirow[b]{2}{*}{ D5 } & \multirow[b]{2}{*}{ D6 } & \multirow[b]{2}{*}{ D7 } & \multirow[b]{2}{*}{ D8 } & \multirow[b]{2}{*}{ D9 } & \multirow[b]{2}{*}{ D10 } & \multirow{2}{*}{$p$ value } \\
\hline & & D1 & D2 & D3 & & & & & & & & \\
\hline \multirow{3}{*}{ No. of subjects } & Total & 138 & 139 & 135 & 139 & 138 & 140 & 136 & 137 & 138 & 135 & \\
\hline & Male & 87 & 82 & 85 & 85 & 85 & 88 & 86 & 80 & 86 & 83 & \\
\hline & Female & 53 & 51 & 54 & 53 & 53 & 54 & 53 & 51 & 54 & 52 & \\
\hline Gender, male, $n(\%)$ & Total & $\begin{array}{c}25 \\
(18.1 \%)\end{array}$ & $\begin{array}{c}27 \\
(19.4 \%)\end{array}$ & $\begin{array}{c}46 \\
(34.1 \%)\end{array}$ & $\begin{array}{c}75 \\
(54.0 \%)\end{array}$ & $\begin{array}{c}96 \\
(69.6 \%)\end{array}$ & $\begin{array}{c}91 \\
(65.0 \%)\end{array}$ & $\begin{array}{c}114 \\
(83.8 \%)\end{array}$ & $\begin{array}{c}115 \\
(83.9 \%)\end{array}$ & $\begin{array}{c}128 \\
(92.8 \%)\end{array}$ & $\begin{array}{c}130 \\
(96.3)\end{array}$ & $<0.001$ \\
\hline \multirow{3}{*}{$\begin{array}{l}\text { Age (years), mean } \\
\text { (SD) }\end{array}$} & \multirow{3}{*}{$\begin{array}{c}\text { Total } \\
\text { Male } \\
\text { Female }\end{array}$} & $\begin{array}{l}43.0 \\
(8.4)\end{array}$ & $\begin{array}{l}44.0 \\
(8.1)\end{array}$ & $\begin{array}{l}42.2 \\
(9.0)\end{array}$ & $\begin{array}{l}42.7 \\
(8.5)\end{array}$ & $\begin{array}{l}39.7 \\
(8.5)\end{array}$ & $\begin{array}{l}38.1 \\
(8.0)\end{array}$ & $\begin{array}{l}37.0 \\
(8.9)\end{array}$ & $\begin{array}{l}35.9 \\
(8.5)\end{array}$ & $\begin{array}{l}36.1 \\
(8.5)\end{array}$ & $\begin{array}{l}38.1 \\
(8.9)\end{array}$ & $<0.001$ \\
\hline & & $\begin{array}{l}43.2 \\
(7.8)\end{array}$ & $\begin{array}{l}44.2 \\
(7.9)\end{array}$ & $\begin{array}{l}40.6 \\
(8.7)\end{array}$ & $\begin{array}{l}37.7 \\
(8.0)\end{array}$ & $\begin{array}{l}37.9 \\
(8.0)\end{array}$ & $\begin{array}{l}35.3 \\
(8.8)\end{array}$ & $\begin{array}{l}35.3 \\
(8.7)\end{array}$ & $\begin{array}{l}36.3 \\
(8.4)\end{array}$ & $\begin{array}{l}37.0 \\
(8.1)\end{array}$ & $\begin{array}{l}38.5 \\
(9.5)\end{array}$ & $<0.001$ \\
\hline & & $\begin{array}{l}43.0 \\
(7.9)\end{array}$ & $\begin{array}{l}43.5 \\
(8.5)\end{array}$ & $\begin{array}{l}44.5 \\
(8.4)\end{array}$ & $\begin{array}{l}44.0 \\
(8.7)\end{array}$ & $\begin{array}{l}41.3 \\
(8.9)\end{array}$ & $\begin{array}{l}41.4 \\
(9.8)\end{array}$ & $\begin{array}{l}40.3 \\
(9.1)\end{array}$ & $\begin{array}{l}39.6 \\
(9.0)\end{array}$ & $\begin{array}{l}39.5 \\
(8.0)\end{array}$ & $\begin{array}{l}37.4 \\
(8.6)\end{array}$ & $<0.001$ \\
\hline \multirow{3}{*}{$\begin{array}{l}\mathrm{SUA}(\mu \mathrm{mol} / \mathrm{l}), \text { mean } \\
(\mathrm{SD})\end{array}$} & Total & $\begin{array}{l}194.1 \\
(24.6)\end{array}$ & $\begin{array}{c}240.3 \\
(9.6)\end{array}$ & $\begin{array}{c}268.8 \\
(7.5)\end{array}$ & $\begin{array}{l}294.1 \\
(7.0)\end{array}$ & $\begin{array}{l}319.8 \\
(7.7)\end{array}$ & $\begin{array}{c}344.8 \\
(7.2)\end{array}$ & $\begin{array}{c}370.9 \\
(7.8)\end{array}$ & $\begin{array}{c}397.6 \\
(8.1)\end{array}$ & $\begin{array}{l}434.7 \\
(15.8)\end{array}$ & $\begin{array}{l}527.3 \\
(57.9)\end{array}$ & $<0.001$ \\
\hline & Male & $\begin{array}{l}240.6 \\
(30.6)\end{array}$ & $\begin{array}{l}391.9 \\
(7.7)\end{array}$ & $\begin{array}{c}317.3 \\
(7.1)\end{array}$ & $\begin{array}{c}340.2 \\
(6.5)\end{array}$ & $\begin{array}{c}362.9 \\
(5.5)\end{array}$ & $\begin{array}{c}383.0 \\
(6.0)\end{array}$ & $\begin{array}{l}403.0 \\
(6.6)\end{array}$ & $\begin{array}{l}426.9 \\
(8.8)\end{array}$ & $\begin{array}{l}469.4 \\
(15.1)\end{array}$ & $\begin{array}{l}554.1 \\
(56.6)\end{array}$ & $<0.001$ \\
\hline & Female & $\begin{array}{l}173.0 \\
(24.9)\end{array}$ & $\begin{array}{c}208.6 \\
(5.3)\end{array}$ & $\begin{array}{c}228.3 \\
(5.0)\end{array}$ & $\begin{array}{l}244.8 \\
(4.2)\end{array}$ & $\begin{array}{c}258.8 \\
(3.6)\end{array}$ & $\begin{array}{c}273.9 \\
(5.1)\end{array}$ & $\begin{array}{c}293.2 \\
(6.3)\end{array}$ & $\begin{array}{c}318.0 \\
(9.0)\end{array}$ & $\begin{array}{c}346.4 \\
(8.5)\end{array}$ & $\begin{array}{l}409.6 \\
(46.6)\end{array}$ & $<0.001$ \\
\hline \multirow{3}{*}{$\begin{array}{l}\mathrm{LDH} \\
n(\%)\end{array}$} & Total & $\begin{array}{c}81 \\
(58.7 \%)\end{array}$ & $\begin{array}{c}76 \\
(54.7 \%)\end{array}$ & $\begin{array}{c}63 \\
(46.7 \%)\end{array}$ & $\begin{array}{c}68 \\
(48.9 \%)\end{array}$ & $\begin{array}{c}67 \\
(48.6 \%)\end{array}$ & $\begin{array}{c}63 \\
(45.0 \%)\end{array}$ & $\begin{array}{c}61 \\
(44.9 \%) 3\end{array}$ & $\begin{array}{c}58 \\
(42.3 \%)\end{array}$ & $\begin{array}{c}66 \\
(47.8 \%)\end{array}$ & $\begin{array}{c}88 \\
(65.2 \%)\end{array}$ & 0.003 \\
\hline & Male & $\begin{array}{c}50 \\
(57.5 \%)\end{array}$ & $\begin{array}{c}43 \\
(52.4 \%)\end{array}$ & $\begin{array}{c}45 \\
(52.9 \%)\end{array}$ & $\begin{array}{c}35 \\
(41.2 \%)\end{array}$ & $\begin{array}{c}35 \\
(41.2 \%)\end{array}$ & $\begin{array}{c}36 \\
(40.9 \%)\end{array}$ & $\begin{array}{c}6 \\
(41.9 \%)\end{array}$ & $\begin{array}{c}32 \\
(40.0 \%)\end{array}$ & $\begin{array}{c}57 \\
(66.3 \%)\end{array}$ & $\begin{array}{c}53 \\
(63.9 \%)\end{array}$ & $<0.001$ \\
\hline & Female & $\begin{array}{c}30 \\
(56.6 \%)\end{array}$ & $\begin{array}{c}30 \\
(58.8 \%)\end{array}$ & $\begin{array}{c}29 \\
(53.7 \%)\end{array}$ & $\begin{array}{c}32 \\
(60.4 \%)\end{array}$ & $\begin{array}{c}19 \\
(35.8 \%)\end{array}$ & $\begin{array}{c}27 \\
(50.0 \%)\end{array}$ & $\begin{array}{c}23 \\
(43.4 \%)\end{array}$ & $\begin{array}{c}22 \\
(43.1 \%)\end{array}$ & $\begin{array}{c}26 \\
(48.1 \%)\end{array}$ & $\begin{array}{c}31 \\
(59.6 \%)\end{array}$ & 0.161 \\
\hline
\end{tabular}

Data on age and SUA are given as the means \pm SD. Statistical analysis by one-way ANOVA test or $t$-test. SUA: serum uric acid; IDD: intervertebral disc degeneration.

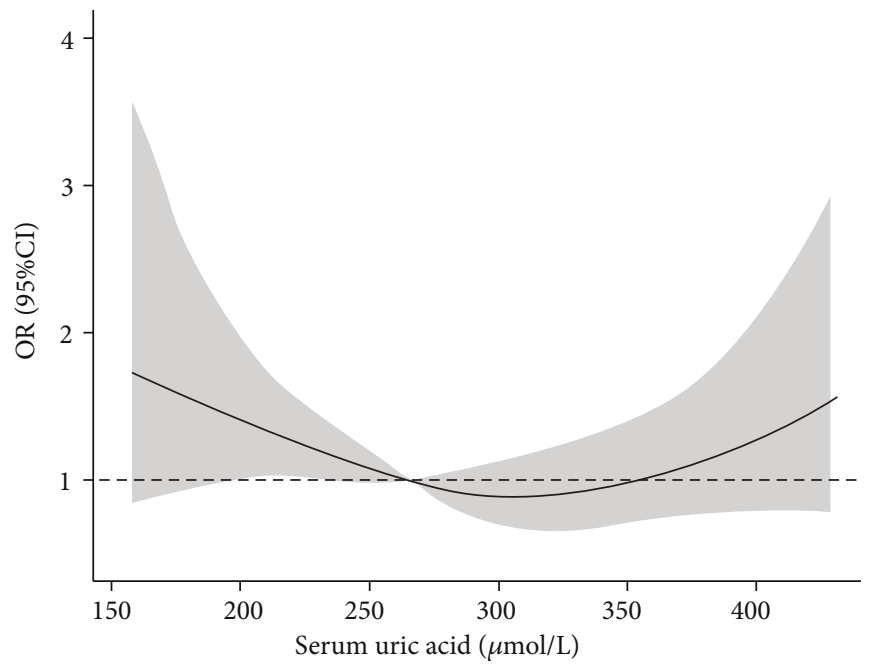

FIgURE 1: Single factor ORs for IDD by SUA level in male population.

inflammatory factors, among others will lead to changes in the composition of the ECM of the IVD [20,23].

In this present study, logistic regression analysis showed that in the male population, the LDH incidence was higher in the percentile range of SUA $>80 \%$ and $<20 \%$. However, in the female population, the LDH incidence was higher only when SUA was only in the $<20 \%$ percentile range. This may be because the female's SUA level is lower than that in the males [24], such that the SUA level of women is relatively lower in the percentile range of $>80 \%$. The results of restricted cubic spline regression analysis after adjusting for confounding factors showed that SUA was a risk factor 


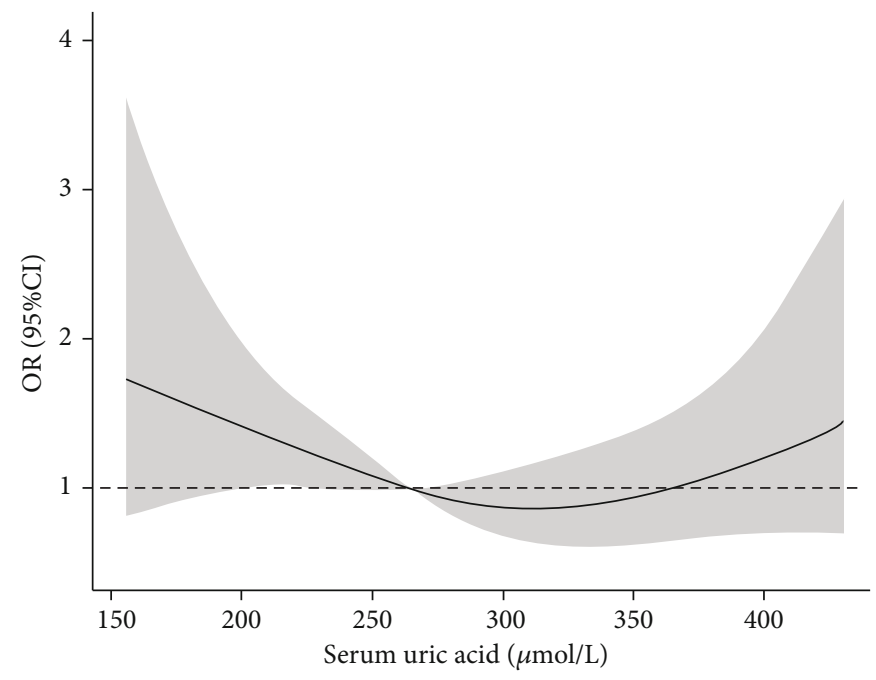

Figure 2: Multivariable-adjusted ORs for IDD by SUA level in male population. Age, BMI, drinking, and smoking were adjusted.

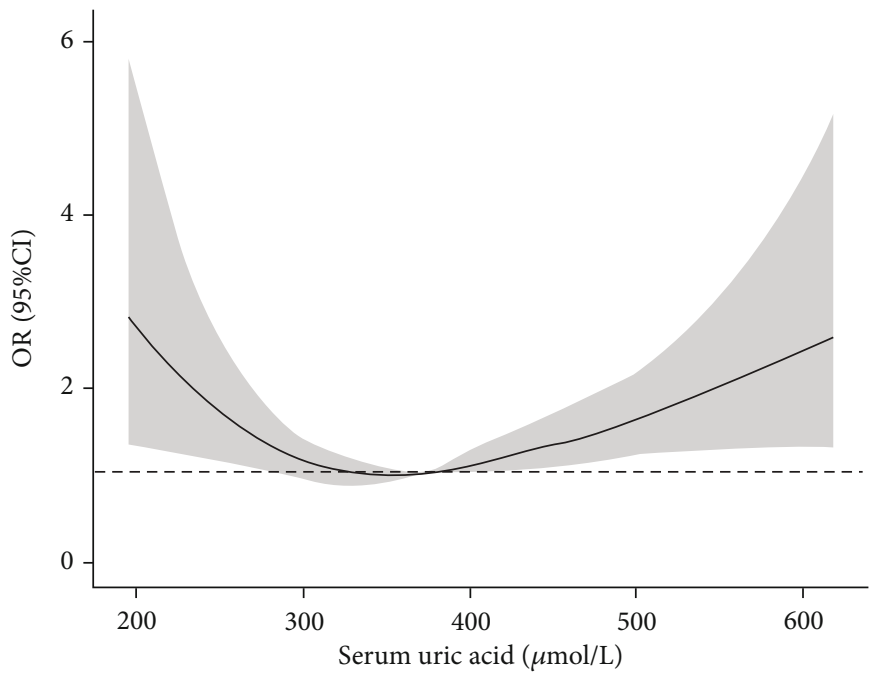

FIGURE 3: Single factor ORs for IDD by SUA level in female population.

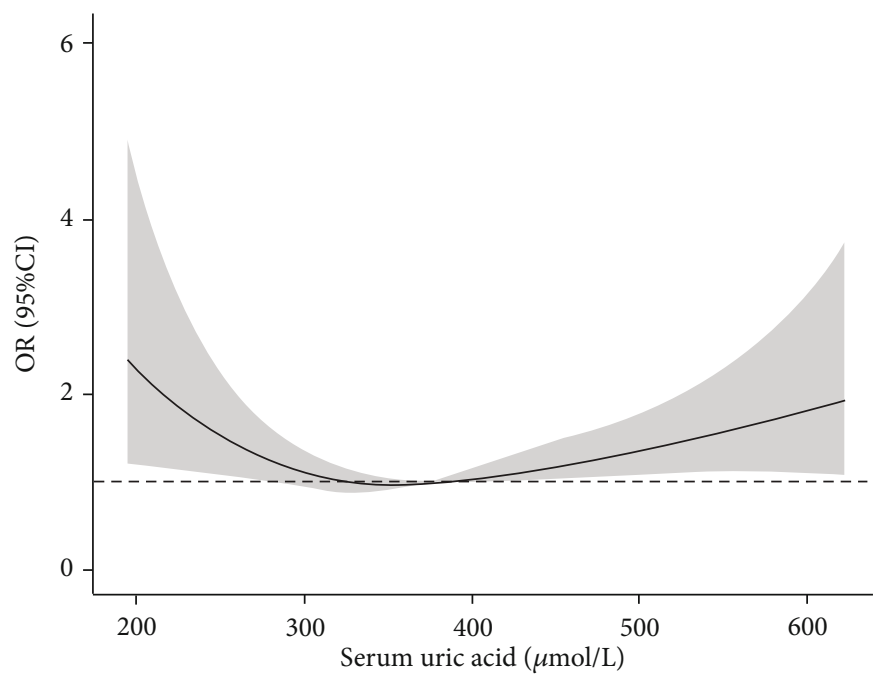

FIgURe 4: Multivariable-adjusted ORs for IDD by SUA level in female population. Age, BMI, drinking, and smoking were adjusted. 
TABLE 4: Univariate logistic regression analysis and the risk of IDD.

\begin{tabular}{|c|c|c|c|c|c|c|}
\hline \multirow{2}{*}{ Deciles of SUA } & \multicolumn{2}{|l|}{ Male } & \multicolumn{2}{|l|}{ Female } & \multicolumn{2}{|l|}{ Total } \\
\hline & OR $(95 \%$ CI $)$ & $p$ value & OR $(95 \% \mathrm{CI})$ & $p$ value & OR $(95 \% \mathrm{CI})$ & $p$ value \\
\hline$\leq 20 \%$ & $1.764(1.144,2.719)$ & 0.010 & $1.788(1.032,3.097)$ & 0.038 & $1.693(1.209,2.372)$ & 0.002 \\
\hline $20 \%-40 \%$ & $1.281(0.832,1.973)$ & 0.261 & $1.739(1.008,2.998)$ & 0.047 & $1.186(0.847,1.660)$ & 0.322 \\
\hline $40 \%-60 \%$ & $1.003(0.651,1.547)$ & 0.989 & $0.989(0.573,1.705)$ & 0.967 & $1.137(0.813,1.590)$ & 0.454 \\
\hline $60 \%-80 \%$ & 1 & & 1 & & 1 & \\
\hline$\geq 80 \%$ & $2.687(1.726,4.182)$ & $<0.001$ & $1.525(0.885,2.628)$ & 0.129 & $1.675(1.194,2.349)$ & 0.003 \\
\hline
\end{tabular}

IDD: intervertebral disc degeneration; SUA: serum uric acid; OR: odds ratio; CI: confidence interval.

TABLE 5: Multivariate logistic regression analysis and the risk of IDD.

\begin{tabular}{|c|c|c|c|c|c|c|}
\hline \multirow{2}{*}{ Deciles of SUA } & \multicolumn{2}{|l|}{ Male } & \multicolumn{2}{|l|}{ Female } & \multicolumn{2}{|l|}{ Total } \\
\hline & OR $(95 \% \mathrm{CI})$ & $p$ value & OR $(95 \% \mathrm{CI})$ & $p$ value & OR $(95 \% \mathrm{CI})$ & $p$ value \\
\hline$\leq 20 \%$ & $1.922(1.169,3.161)$ & 0.010 & $1.951(1.091,3.486)$ & 0.024 & $1.821(1.125,2.946)$ & 0.0590 .0 \\
\hline $20 \%-40 \%$ & $1.321(0.846,2.063)$ & 0.220 & $1.672(0.947,2.951)$ & 0.076 & $1.473(0.986,2.202)$ & 15 \\
\hline $40 \%-60 \%$ & $1.024(0.661,1.586)$ & 0.916 & $0.967(0.553,1.690)$ & 0.905 & $1.136(0.802,1.609)$ & 0.472 \\
\hline $60 \%-80 \%$ & 1 & & 1 & & 1 & \\
\hline$\geq 80 \%$ & $2.800(1.766,4.439)$ & $<0.001$ & $1.504(0.858,2.639)$ & 0.154 & $1.701(1.186,2.438)$ & 0.004 \\
\hline
\end{tabular}

IDD: intervertebral disc degeneration; SUA: serum uric acid; OR: odds ratio; CI: confidence interval.

for LDH when SUA was lower than $265.3 \mu \mathrm{mol} / 1$ or higher than $363.6 \mu \mathrm{mol} / 1$ in the male population, while these two critical values were $324.1 \mu \mathrm{mol} / 1$ and $375.6 \mu \mathrm{mol} / 1$ in the female population, respectively. This result showed that there is a U-shaped relationship between the SUA level and the LDH incidence. In the male population, the critical low value is lower than that in the female population, which makes this $\mathrm{U}$-shaped relationship more obvious. This $\mathrm{U}$ shaped relationship is similar to some previous studies [25, 26]. Mori et al. [26] found a U-shaped relationship between the SUA level and a decline in renal function. Zhang et al. [25] found a U-shaped association between SUA and allcause mortality in a normal-weight population.

Some studies have found that HUA is a risk factor for some diseases [4, 27, 28]. Kleber et al. [28] found that a high SUA level is causally related to adverse cardiovascular outcomes, particularly sudden cardiac death. A systematic review by Li et al. [27] reported that SUA level increased elevated SUA level showed an increased risk for the development of chronic renal dysfunction. We believe that high SUA concentrations may also induce IDD. A high SUA level can promote the generation of oxygen free radicals, damage vascular endothelial cells, and cause oxidative modification of LDL-C and lead to atherosclerosis [22, 29, 30]. These changes can affect the nutrient supply to the IVD [20]. An excessive UA concentration in IVD tissue will damage the functions of mitochondria and lysosomes and lead to apoptosis [31]. The high osmotic pressure generated by HUA also plays an important role in IDD. Mavrogonatou and Kletsas [32] found that the hypertonic state can affect the cell cycle, cause cell volume changes, and damage DNA. The hypertonic state can inhibit PDGF- or IGF-I-mediated DNA synthesis in nucleus pulposus cells, thereby exacerbating IDD [33]. In addition, too high a UA concentration can produce urate crystals in the IVD. When urate accumulates on the endplate, endplateitis and bone destruction of the endplate will occur, which will affect the ability of the cartilage endplate to deliver nutrients and oxygen to the IVD [34].

Contrary to the destructive effect, UA, as an antioxidant, also plays an important protective role in the body. Oxidative stress is associated with many physiological and pathological reactions, including aging and cancer [6].UA is one of the most important antioxidant in the human body, which is an oxidizable substrate that can act as an electron donor to prevent oxidative damage [35-38]. UA has a strong scavenging effect on reactive oxygen species (ROS) [35]. ROS include free radicals and nonradical oxygen intermediates (peroxides), including superoxide anion $\left(\mathrm{O}_{2}{ }^{--}\right)$, hydrogen peroxide $\left(\mathrm{H}_{2} \mathrm{O}_{2}\right)$, hydroxyl radical $\left(\mathrm{OH}^{-}\right)$, and singlet oxygen $\left({ }^{1} \mathrm{O}_{2}\right)$. These substances can interact with cell components and cause cell damage [37, 39]. IVD cells can generate ROS, and ROS overexpression has also been observed in degenerated IVD. ROS are important mediators in the signal network of IVD cells. They regulate the matrix metabolism, proinflammatory phenotype, apoptosis, autophagy, and aging of IVD cells. The oxidative stress involved in ROS not only exacerbates the ECM degradation but also promotes the reduction of the number of living cells in the IVD [40]. UA is also a specific inhibitor of peroxynitrite $\left(\mathrm{ONOO}^{-}\right)$[36]. Peroxynitrite is a strong oxidant, which can cause tyrosine nitrosation, and is an indicator of excessive ROS production [41]. Tyrosine nitrosation was found in human nucleus pulposus tissue specimens, and with IDD progression, the percentage of tyrosine's nitrosation increased [40]. We believe that when the SUA level is lower, the antioxidant effect provided by UA is weakened, which may accelerate the progression of IDD. 
There are some limitations in the present study. First, the sample size was relatively small, with only 1375 patients included in the study, which may be statistically biased, leading to inaccurate conclusions. To more clearly clarify the relationship between SUA and IDD, further prospective, multicenter, large-sample studies are needed. In addition, this study explored the relationship between SUA and IDD. There are many factors affecting the SUA level, including a patient's genetic factors, eating habits, and kidney diseases among others. Therefore, we need to perform further research to exclude the influence of these factors. Finally, this study only obtained results from the analysis of clinical data. Therefore, further basic research is needed to determine the relationship between SUA and IDD.

\section{Conclusion}

The results of our study suggested that there is a U-shaped relationship between SUA and IDD. A lower or higher SUA level is a risk factor for IDD. This relationship may be due to the dual effect of SUA on IVD. The existence of the U-shaped relationship should allow the definition of a target protective SUA level against the risk for IDD. An enhanced understanding and further research on this $U$ shaped relationship may lead to new approaches for reducing the risk for IDD.

$\begin{array}{ll}\text { Abbreviations } \\ \text { SUA: } & \text { Serum uric acid } \\ \text { IDD: } & \text { Intervertebral disc degeneration } \\ \text { LDH: } & \text { Lumbar disc herniation } \\ \text { BMI: } & \text { Body mass index } \\ \text { OR: } & \text { Odd ratio } \\ \text { IVD: } & \text { Intervertebral disc } \\ \text { ECM: } & \text { Extracellular matrix } \\ \text { UA: } & \text { Uric acid } \\ \mathrm{HUA}: & \text { Hyperuricemia } \\ \text { ROS: } & \text { Reactive oxygen species } \\ \mathrm{O}_{2}{ }^{--}: & \text {Superoxide anion } \\ \mathrm{H}_{2} \mathrm{O}{ }_{2}: & \text { Hydrogen peroxide } \\ \mathrm{OH}^{1}: & \text { Hydroxyl radical } \\ { }^{1} \mathrm{O}_{2}: & \text { Singlet oxygen } \\ \mathrm{ONOO}^{-}: & \text {Peroxynitrite. }\end{array}$

\section{Data Availability}

The datasets generated and/or analyzed during the present study are available from the corresponding author upon reasonable request.

\section{Ethical Approval}

The present study was performed according to the guidelines of the Ethics Committee of the First Affiliated Hospital of Dalian Medical University (PJ-KS-KY-2021-86).

\section{Disclosure}

The funders had no role in the study design, data collection and analysis, decision to publish, or preparation of the manuscript.

\section{Conflicts of Interest}

The authors declare that they have no competing interest.

\section{Authors' Contributions}

All authors contributed to the conception and design of the study, or acquisition of data, or analysis and interpretation of data; drafting the article or revising it critically for important intellectual content; and the final approval of the version to be submitted. ZL (lizhonghaispine@126.com) takes responsibility for the integrity of the work as a whole, from inception to finished article. Ming Yang, Naiguo Wang, and Wentao Zhang contributed equally to the manuscript and should be considered co-first authors.

\section{Acknowledgments}

We would like to thank all the participants in the studies. The authors would like to thank Dr. Yushan Wei for advice on the statistical analyses. This study was supported by the LiaoNing Revitalization Talents Program (XLYC1807131), the Science and Technology Innovation Foundation of Dalian (2020JJ27SN070), and the open project of Key Laboratory for Micro/Nano Technology and System of Liaoning Province, Dalian University of Technology (20210101).

\section{References}

[1] M. Ghannam, F. Jumah, S. Mansour et al., "Surgical anatomy, radiological features, and molecular biology of the lumbar intervertebral discs," Clinical Anatomy, vol. 30, no. 2, pp. 251-266, 2017.

[2] F. Zhang, X. Zhao, H. Shen, and C. Zhang, "Molecular mechanisms of cell death in intervertebral disc degeneration (review)," International Journal of Molecular Medicine, vol. 37, no. 6, pp. 1439-1448, 2016.

[3] T. Oichi, Y. Taniguchi, Y. Oshima, S. Tanaka, and T. Saito, "Pathomechanism of intervertebral disc degeneration," JOR Spine, vol. 3, no. 1, article e1076, 2020.

[4] D. I. Feig, D. H. Kang, and R. J. Johnson, "Uric acid and cardiovascular risk," The New England Journal of Medicine, vol. 359, no. 17, pp. 1811-1821, 2008.

[5] M. Chen-Xu, C. Yokose, S. K. Rai, M. H. Pillinger, and H. K. Choi, "Contemporary prevalence of gout and hyperuricemia in the United States and decadal trends: the National Health and Nutrition Examination Survey, 2007-2016," Arthritis \& Rhematology, vol. 71, no. 6, pp. 991-999, 2019.

[6] B. Álvarez-Lario and J. Macarrón-Vicente, "Uric acid and evolution," Rheumatology, vol. 49, no. 11, pp. 2010-2015, 2010.

[7] Y. du, C. P. Chen, C. Y. Tseng, Y. Eisenberg, and B. L. Firestein, "Astroglia-mediated effects of uric acid to protect spinal cord neurons from glutamate toxicity," Glia, vol. 55, no. 5, pp. 463-472, 2007. 
[8] S. Y. Pan, R. J. Cheng, Z. J. Xia, Q. P. Zhang, and Y. Liu, "Risk of dementia in gout and hyperuricaemia: a meta-analysis of cohort studies," BMJ Open, vol. 11, no. 6, article e041680, 2021.

[9] S. Manifar, A. Rahimzamani, M. Shirkhoda, M. N. Ghamsari, and M. Bakhshi, "Role of serum uric acid as a protective biomarker in patients with different histopathological grades of oral squamous cell carcinoma: a case-control study," BioMed Research International, vol. 2020, Article ID 5185423, 5 pages, 2020.

[10] C. H. Tsai, Y. J. Chen, H. C. Hsu, and H. T. Chen, "Bacteremia coexisting with tophaceous gout of the spine mimicking spondylodiscitis: a case report," Spine, vol. 34, no. 2, pp. E106E109, 2009.

[11] K. S. Suk, K. T. Kim, S. H. Lee, S. W. Park, and Y. K. Park, "Tophaceous gout of the lumbar spine mimicking pyogenic discitis," The Spine Journal, vol. 7, no. 1, pp. 94-99, 2007.

[12] Y. Chang, M. Yang, Y. Zhang, G. Xu, and Z. Li, "Does hyperuricemia correlate with intervertebral disc degeneration?" Medical Hypotheses, vol. 140, p. 109673, 2020.

[13] J. Dowdell, M. Erwin, T. Choma, A. Vaccaro, J. Iatridis, and S. K. Cho, "Intervertebral disk degeneration and repair," Neurosurgery, vol. 80, no. 3s, pp. S46-s54, 2017.

[14] C. K. Kepler, R. K. Ponnappan, C. A. Tannoury, M. V. Risbud, and D. G. Anderson, "The molecular basis of intervertebral disc degeneration," The Spine Journal, vol. 13, no. 3, pp. 318330, 2013.

[15] S. K. Mirza and A. A. White III, "Anatomy of intervertebral disc and pathophysiology of herniated disc disease," Journal of Clinical Laser Medicine \& Surgery, vol. 13, no. 3, pp. 131142, 1995.

[16] F. Marchand and A. M. Ahmed, "Investigation of the laminate structure of lumbar disc anulus fibrosus," Spine, vol. 15, no. 5, pp. 402-410, 1990.

[17] K. Ogata and L. A. Whiteside, "1980 Volvo award winner in basic science. Nutritional pathways of the intervertebral disc. An experimental study using hydrogen washout technique," Spine, vol. 6, no. 3, pp. 211-216, 1981.

[18] R. J. Moore, “The vertebral endplate: disc degeneration, disc regeneration," European Spine Journal, vol. 15, Suppl 3, pp. 333-337, 2006.

[19] R. J. Moore, "The vertebral end-plate: what do we know?," European Spine Journal, vol. 9, no. 2, pp. 92-96, 2000.

[20] J. P. Urban and S. Roberts, "Degeneration of the intervertebral disc," Arthritis Research \& Therapy, vol. 5, no. 3, pp. 120-130, 2003.

[21] A. Tanaka, I. Taguchi, H. Teragawa et al., "Febuxostat does not delay progression of carotid atherosclerosis in patients with asymptomatic hyperuricemia: a randomized, controlled trial," PLoS Medicine, vol. 17, no. 4, article e1003095, 2020.

[22] X. Jiang, M. Li, Q. Yang, L. du, J. du, and J. Zhou, "Oxidized low density lipoprotein and inflammation in gout patients," Cell Biochemistry and Biophysics, vol. 69, no. 1, pp. 65-69, 2014.

[23] J. C. Iatridis, J. Kang, R. Kandel, and M. V. Risbud, "New horizons in spine research: intervertebral disc repair and regeneration," Journal of Orthopaedic Research, vol. 35, no. 1, pp. 5-7, 2017.

[24] D. Adamopoulos, C. Vlassopoulos, B. Seitanides, P. Contoyiannis, and P. Vassilopoulos, "The relationship of sex steroids to uric acid levels in plasma and urine," Acta Endocrinologica, vol. 85, no. 1, pp. 198-208, 1977.

[25] S. Zhang, L. LIU, Y. Q. Huang, K. Lo, and Y. Q. Feng, “A Ushaped association between serum uric acid with all-cause mortality in normal-weight population," Postgraduate Medicine, vol. 132, no. 4, pp. 391-397, 2020.

[26] K. Mori, M. Furuhashi, M. Tanaka et al., "U-shaped relationship between serum uric acid level and decline in renal function during a 10 -year period in female subjects: BOREASCKD2," Hypertension Research, vol. 44, no. 1, pp. 107-116, 2021.

[27] L. Li, C. Yang, Y. Zhao, X. Zeng, F. Liu, and P. Fu, "Is hyperuricemia an independent risk factor for new-onset chronic kidney disease?: a systematic review and meta-analysis based on observational cohort studies," BMC Nephrology, vol. 15, no. 1, p. 122, 2014.

[28] M. E. Kleber, G. Delgado, T. B. Grammer et al., "Uric acid and cardiovascular events: a Mendelian randomization study," Journal of the American Society of Nephrology, vol. 26, no. 11, pp. 2831-2838, 2015.

[29] W. J. Ho, W. P. Tsai, K. H. Yu et al., "Association between endothelial dysfunction and hyperuricaemia," Rheumatology, vol. 49, no. 10, pp. 1929-1934, 2010.

[30] Jesse Dawson, Terry Quinn, and Matthew Walters, "Uric acid reduction: a new paradigm in the management of cardiovascular risk?," Current Medicinal Chemistry, vol. 14, no. 17, pp. 1879-1886, 2007.

[31] K. L. Rock, H. Kataoka, and J. J. Lai, "Uric acid as a danger signal in gout and its comorbidities," Nature Reviews Rheumatology, vol. 9, no. 1, pp. 13-23, 2013.

[32] E. Mavrogonatou and D. Kletsas, "Differential response of nucleus pulposus intervertebral disc cells to high salt, sorbitol, and urea," Journal of Cellular Physiology, vol. 227, no. 3, pp. 1179-1187, 2012.

[33] E. Mavrogonatou and D. Kletsas, "Effect of varying osmotic conditions on the response of bovine nucleus pulposus cells to growth factors and the activation of the ERK and Akt pathways," Journal of Orthopaedic Research, vol. 28, no. 10, pp. 1276-1282, 2010.

[34] B. Peng, S. Hou, Q. Shi, and L. Jia, "The relationship between cartilage end-plate calcification and disc degeneration: an experimental study," Chinese Medical Journal, vol. 114, no. 3, pp. 308-312, 2001.

[35] M. G. Simic and S. V. Jovanovic, "Antioxidation mechanisms of uric acid," Journal of the American Chemical Society, vol. 111, no. 15, pp. 5778-5782, 1989.

[36] G. K. Glantzounis, E. Tsimoyiannis, A. Kappas, and D. Galaris, "Uric acid and oxidative stress," Current Pharmaceutical Design, vol. 11, no. 32, pp. 4145-4151, 2005.

[37] B. N. Ames, R. Cathcart, E. Schwiers, and P. Hochstein, "Uric acid provides an antioxidant defense in humans against oxidant- and radical-caused aging and cancer: a hypothesis," Proceedings of the National Academy of Sciences of the United States of America, vol. 78, no. 11, pp. 6858-6862, 1981.

[38] S. Amaro, L. Llull, A. Renú et al., "Uric acid improves glucosedriven oxidative stress in human ischemic stroke," Annals of Neurology, vol. 77, no. 5, pp. 775-783, 2015.

[39] J. Checa and J. M. Aran, "Reactive oxygen species: drivers of physiological and pathological processes," Journal of Inflammation Research, vol. Volume 13, pp. 1057-1073, 2020. 
[40] C. Feng, M. Yang, M. Lan et al., "ROS: crucial intermediators in the pathogenesis of intervertebral disc degeneration," Oxidative Medicine and Cellular Longevity, vol. 2017, Article ID 5601593, 12 pages, 2017.

[41] N. Hogg, V. M. Darley-Usmar, M. T. Wilson, and S. Moncada, "Production of hydroxyl radicals from the simultaneous generation of superoxide and nitric oxide," The Biochemical Journal, vol. 281, no. 2, pp. 419-424, 1992. 